\title{
Breast-feeding in sub-Saharan Africa: outlook for 2000
}

\author{
Alexander RP Walker* and Fatima I Adam \\ Human Biochemistry Research Unit, School of Pathology of the University of the Witwatersrand, \\ and the South African Institute for Medical Research, PO Box 1038, Johannesburg 2000, South Africa
}

Submitted 5 August 1999: Accepted 17 January 2000

\begin{abstract}
The World Health Organization (WHO) has stressed that 1.5 million infants die annually, unnecessarily, from deprival or from insufficiency of breast milk. Hence, the need for its maximal use, very particularly in impoverished populations, such as those in sub-Saharan Africa. In many developed populations, a generation ago the practice was very low, but now it has risen considerably. In contrast, in Africa and in most developing populations, despite the far greater need for breast-feeding, the practice is tending to decrease, especially among urban mothers. While the most common reasons given concern insufficiency of breast milk and employment of mothers, the latter, especially urban mothers, are under strong and increasing pressure to use proprietary replacement foods. These are often made up unsatisfactorily and are contaminated. Also influential are the often less than enthusiastic, and confusing, attitudes of staff at clinics and hospitals, albeit, due in part to their very heavy workloads. Additionally, there is society's relatively indifferent attitude to breastfeeding. Currently, a hugely adverse factor is the danger of human immunodeficiency virus (HIV) transference from seropositive mothers to their infants - in some African countries almost half of antenatal mothers are infected. Chances of early control of the infection are remote. However, apart from this danger, and from the pressure from replacement food companies, the outlook for breast-feeding practice in many African countries is unlikely to improve significantly until greater encouragement is given from State, local and other health authorities.
\end{abstract}

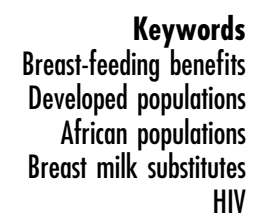

What is the magnitude of the problem at issue? How important to the health of the infant is the choice of breastfeeding or not breast-feeding? As noted in a recent editorial $^{1}$, WHO has estimated that 1.5 million infant deaths per year could have been prevented had they been breast-fed $^{2}$. In a low income country, evidence indicates that artificial feeding would produce an excess of postneonatal deaths at 6 months ranging from 13\% at 10\% prevalence of artificial feeding, to $59 \%$ at $100 \%$ of artificial feeding ${ }^{3}$.

It is noteworthy that compared with the recent past, developed populations are experiencing an increase in breast-feeding initiation rates and in the duration of the practice; whereas, unfortunately, and in contrast, in developing populations the rate and the duration of breastfeeding appear to be decreasing, especially among urban mothers $^{4-6}$.

In seeking to throw light on the outlook for breastfeeding in sub-Saharan African populations, after briefly describing the benefits from the practice, the intention is to indicate trends in this regard, past and present. This will be done, first, for perspective, in developed populations and then in sub-Saharan African populations. Next, primary influencing factors will be discussed, and then, from the information gathered, an answer will be sought - what are the likely prospects for breast-feeding in African mothers in the current millennium?

\section{Benefits from breast-feeding}

As repeatedly emphasized, breast-feeding is cheap, convenient, safer and emotionally satisfying ${ }^{6-8}$. There is a special mother-infant bond. Milk supply is tailored to meet the baby's needs; and, further, in the case of the prematurely delivered infant, the foodstuff has a high concentration of growth factors which tends to be maximal in day one colostrum. The practice provides much less chance of contamination; in this respect, evidence is strongest for protection against gastrointestinal infections. Benefits are greatest in lower socioeconomic groups and in those communities who have poor water and sanitation facilities. The rewards are thus nutritional, immunological and psychological. Regarding infant mortality rate (IMR), benefits were demonstrated in an early study made in Chile, where there were three times as many deaths among babies given bottle feeds before the age of 3 months than among those who were breast-fed ${ }^{9}$. A further benefit of high relevance to poor populations who still have large families, concerns the fact that it takes longer for women who breast-feed their children to become pregnant than 
for those who do not breast-feed. Mothers can thus benefit from wider birth intervals which enable them to recover their health. The anovular and amenorrhoea period is most effective when sucking is regular, frequent, intense and prolonged, and extends into the second year of lactation ${ }^{10}$.

\section{Breast-feeding trends in developed populations}

In millennia past, breast-feeding was virtually invariable in the masses and was continued for long periods, since there were no ready replacement foods ${ }^{11}$. It is important to appreciate that as little as a generation ago, breast-feeding was practised by the minority of mothers. Thus, in the UK, in the 1970s, according to a major report, it is scarcely believable that in some parts of the country less than a third of mothers even tried to initiate lactation; moreover, in the case of most lactating mothers, breast-feeding had ceased within a month ${ }^{12}$. In the USA during the same period, observations revealed that only $10 \%$ of infants were breast-fed until 4 months ${ }^{13}$. Furthermore, the practice was less common among lower income mothers compared with those in better circumstances. In Johannesburg, South Africa, in the white population, one enquiry revealed that only $50 \%$ of mothers had initiated breast-feeding ${ }^{14}$; at the extreme, at a maternity hospital in Cape Town, only 5-7\% of mothers were still breast-feeding at 6 weeks ${ }^{15}$.

Turning to more recent times, in the USA, in 1989, 58.5\% of white mothers began to breast-feed their infants in hospital; at 6 months, $21.0 \%$ were still lactating ${ }^{16}$. In a study made in Denmark, the corresponding proportion at 6 months was much higher, $73 \%{ }^{17}$. It is noteworthy that during the same period, while $23 \%$ of African-American mothers initiated breast-feeding, only $6.4 \%$ continued for 6 months ${ }^{14}$. In efforts to increase the practice in the USA, the Healthy People 2000 objective is to raise the breastfeeding initiation rate of $54 \%$, which prevailed in 1988 , to $75 \%$; and from a rate of $21 \%$ at 6 months to $50 \%{ }^{18}$. In a recent review on 'why women fail to breast-feed' it was concluded that the measure of success of those who wish to breast-feed is greatly influenced by medical and midwifery practice ${ }^{19}$.

\section{Breast-feeding trends in sub-Saharan African populations}

In sub-Saharan Africa the situation regarding breastfeeding practice in the past, the situation at present and, of course, the likely future prospects, varies from country to country and within countries - between rural and urban areas, and between the poor and those less in need.

In the far past, breast-feeding was near invariable for $1-2$ years ${ }^{20}$. However, a generation ago, changes in practice began. Thus, in South Africa, in the 1970s, an enquiry on infant feeding practice indicated falls in its frequency and in its duration ${ }^{21}$. For example, in a series of infants studied in Durban, at 6 months 18\% were exclusively breast-fed, in 30\% there was mixed feeding, and 52\% were bottle-fed ${ }^{22}$.

In a recent poster publication from the US Population Reference Bureau, which concerned the general situation within a number of countries, in studies made in subSaharan Africa the initiation rate was $97-99 \%{ }^{23}$. Proportions of those breast-feeding exclusively up to 6 months were noted to be low in Nigeria (1\%) and in Burkina Faso (5\%), but high in Ghana (31\%) and in Uganda (57\%). Proportions breast-feeding but with complementary foods at 6-9 months ranged from 59\% in Burkina Faso and 69\% in Senegal, to 94\% in Kenya and 96\% in Zimbabwe ${ }^{23}$.

In a further general report on the breast-feeding situation in Africa, carried out between 1986 and 1990, it was reported that the initiation of breast-feeding ranged from $92 \%$ to $99 \%$. The median duration ranged from 15.2 to 24.4 months. About $70 \%$ of infants were not exclusively breast-fed during the first 4 months of life ${ }^{24}$.

Currently, in rural areas in Southern Africa, as in the Lesotho Highlands, a baseline cross-sectional study revealed that all infants under 2 years were initially breast-fed ${ }^{25}$. By 3 months, 63\% of mothers had supplemented their breast milk with other milk feeds, mainly with fresh cow's milk. Exclusive breast-feeding was practised only for the first few weeks. In Lebowa, in North West Province, among Pedi mothers, 90\% breast-fed their infants for at least 6 months and $61 \%$ for 18 months. By 3 months, 59\% of mothers had introduced supplementary foods ${ }^{26}$.

Regarding urban dwellers in Soweto, adjacent to Johannesburg, the prevalence of initial breast-feeding was 92\% among mothers, both for those recently urbanized and for those urban born. It was much lower in the case of Indian mothers (73.1\%) and for white mothers $(73.2 \%)^{27}$. At 6 months, $68 \%$ of recently urbanized African mothers were breast-feeding, compared with $48 \%$ of those who were urban born. In Pretoria, all of a series of African mothers studied initiated breast-feeding: proportions were thus high, 90\%, at 3 months and $81 \%$ at 12 months ${ }^{28}$. In the Western Cape, in a low socioeconomic urban area, Kayamandi, $94.6 \%$ of mothers initiated breast-feeding; the proportion still feeding was $67 \%$ at 3-6 months, and $58 \%$ at 6-9 months 5 .

In Lagos, Nigeria, it was reported that women on the lowest of salaries had a mean duration of breast-feeding their last child for 8.0 months, whereas the period was 3.3 months in women in senior professional positions ${ }^{29}$. In the city of Jos, also in Nigeria, a survey revealed that while all mothers initiated breast-feeding, only $55 \%$ started the practice within 24 hours; at 3 months, only $6 \%$ were breast-feeding exclusively ${ }^{30}$. In the Sudan, $77.9 \%$ of mothers believed that breast milk was best for their babies; food supplementation was introduced at 6 months by $82.5 \%$ and household food was introduced by $35.4 \%{ }^{31}$. In rural Somalia, median duration of breast-feeding was 19.5 months. However, infants also received cow's milk by 
cup from the first day of life and onwards ${ }^{32}$. In Kinshasa, Zaire, breast-feeding was universal at birth and remained near or above $90 \%$ until 9 months of age. Bottle-feeding was reported by $10.7 \%$ of mothers; between $85 \%$ and $97 \%$ of all children who were bottle-fed were simultaneously breast-fed ${ }^{33}$.

\section{Reasons for stopping breast-feeding}

In Western Cape, in an enquiry undertaken in a rural and in an urban area, both of which were poor, the main reason given for stopping breast-feeding was that the baby did not want the breast anymore. This was the case with $50.0 \%$ of rural mothers and $68.6 \%$ of urban mothers ${ }^{5}$.

In a recent review, the factors associated with early cessation of breast-feeding and/or early use of supplements were considered to be: milk insufficiency, maternal employment, breast-related problems, a dissatisfied baby or a baby who refused milk, maternal illness and infant illness or prematurity ${ }^{6}$. In addition, considerable responsibility was attributed to the inadequacies of health services, the pressures from breast milk substitute bodies, and, of course, the emergence of the HIV epidemic.

\section{Insufficiency of milk}

The plea of insufficient milk, often made in both developed and developing populations, is expressed in contexts where replacement foods are available, although to a varying extent. Certainly, insufficiency of milk truly prevails in a proportion of cases. An important question, however, arises - were stronger encouragement given by health authorities, would there be a significant lengthening of the duration of breast-feeding? While health care providers are the most influential and trusted sources of information about breast-feeding, many are neither prepared nor able to provide good breast-feeding counselling to their clients. In Cleveland, USA, during the prenatal period, 23\% of mothers received counsel from their obstetrician, $47 \%$ from books and $23 \%$ from classes ${ }^{34}$. Postpartum nurses provided breast-feeding information to $87 \%$ of mothers, whereas obstetricians and pediatricians provided advice to only $27 \%$ and $33 \%$ of mothers, respectively. The study concluded that health care providers should develop better methods of prenatal and postpartum education to enhance breast-feeding initiation and continuation.

An interesting question is: what is the lactation situation in contexts where the mother realizes that should her milk be insufficient there are no alternative foods, and hence her baby will die? It is noteworthy that in a number of highly adverse conditions of diet and environment, breastfeeding was maintainable with a varying degree of success. In World War II this was observed at Belsen concentration camp $^{35}$, at Leningrad during the siege in 1943-1944 $4^{36}$, in starving Holland in $1945^{37}$, and in the prisoner-of-war camps in Singapore ${ }^{38}$. In the latter, breast-feeding was initiated by all mothers and was continued exclusively for
6 months, and partially for a year. Under less severe circumstances, in a number of very poor populations, breast-feeding has been practised for longer than might be expected $^{39}$.

\section{Influence of attitudes of staff in clinics and hospitals}

Bearing in mind the importance of breast-feeding in both developed and developing populations, it is unfortunate, as already indicated ${ }^{19}$, that more positive encouragement is not given by staffs in clinics, hospitals and health departments. Relatively little information is being provided at such places commensurate with the high desirability of maximal breast-feeding. Mothers should be made more aware of the advantages of the practice. Health professionals should support and educate mothers to breastfeed. Additionally, in contrast to the dearth at present, appropriate posters regarding breast-feeding should be displayed in public places, not only in clinics and hospitals, but in post offices and other places where the public spend time waiting.

As evidence of the unsatisfactory situation in western populations, an investigation made in New Zealand revealed a situation of overworked staff, of a lack of health care workers' skills, and the giving of inconsistent advice on breast-feeding ${ }^{40}$. In a major enquiry carried out in London, it was found that in the hospital and in the neonatal unit studied, half of the paediatric staff had received no training in breast-feeding during or after nursing school ${ }^{41}$. It was regretted that there is a lack of studies in the UK on the breast-feeding situation in paediatric units. The inadequacies described supported observations made in an earlier investigation in London, which illustrated the giving of conflicting advice and the general lack of support ${ }^{41}$. Not surprisingly, the same situation applies in numerous other countries, e.g. Saudi Arabia $^{42}$.

In view of the foregoing, the often unsatisfactory situation in African contexts in many respects is understandable. It will be understood, of course, that in the early decades of the twentieth century, the huge majority of African women, especially in rural areas, gave birth to their offspring at home with invariable breast-feeding for prolonged periods ${ }^{43,44}$. No encouragement was needed. In contrast, in an enquiry cited previously ${ }^{5}$, it was reported that by 1979 significantly more infants who were wholly bottle-fed had been born at the local teaching hospital as compared with those who were born in two other units (a maternity hospital and a local obstetric unit) ${ }^{45}$, thereby indicating that although there may be confounding factors, certain hospital policies/practices were not directed towards optimal breast-feeding practices. It was stressed that mothers in communities should not be confused by discrepancies in the messages given. That such do exist among health professionals was clearly illustrated in a survey conducted recently among doctors and nurses in 
KwaZulu Natal. In assessing the extent of their knowledge of some basic principles of lactation, a disturbing lack of unanimity was evidenced about the management of breast-feeding ${ }^{46}$.

In South Africa, in 1997, in realization of situations of the type described ${ }^{47}$, the Department of Health produced a national breast-feeding policy for health workers and health facilities. The aims are to: (i) protect, promote and support breast-feeding; (ii) encourage the use of appropriate complementary foods; (iii) reduce the impact of practices which negatively affect breast-feeding; (iv) ensure that breast-feeding is considered a legitimate reason to grant a mother sick-leave; (v) create a health care system that is free from commercial pressures regarding infant and young child feeding; and (vi) encourage all health facilities to implement the international 'baby friendly hospital' guidelines. The latter have been introduced worldwide, the primary policy being to encourage mothers to breast-feed successfully. There are also numerous support groups, which encourage breast-feeding, such as La Leche League.

As has been repeatedly and authoritatively maintained, the degree of encouragement being devoted to the initiation and to the maintainance of breast-feeding is far behind that being directed by marketing firms for the adoption of replacement foods.

\section{Pressure to use breast milk substitutes}

For several decades, baby food firms have pressured mothers to use breast milk substitutes and have encouraged bottle-feeding. Although such actions are known to jeopardize the health of many children, few governments have considered it to be their duty to restrict or to influence their activities. A generation ago, as an example of the anxiety of medical authorities, in an annotation in the Lancet ${ }^{48}$, entitled 'War on baby foods', the industry was accused of 'promoting its products in communities which cannot use them properly; of using for advertising salesgirls dressed in nurses' uniforms, give-away samples, and free gift gimmicks that persuade mothers to give up breast-feeding.' This castigation was subsequently reiterated in respect of feeding problems in indigent countries: the infant food industry has much blame to bear, because of promotive practices which have thrust unaffordable formulae at countries where breast-feeding was customary and where the vast majority of people are poor and do not have clean homes and a pure water supply or the knowledge ... to make the use of infants foods safe ... ,49.

WHO and the United Nations International Children's Emergency Fund (UNICEF) published a code in 1981 which forbade the provision of free samples to mothers or to health facilities (except for professional research), because of the negative impact on breast-feeding ${ }^{50}$. In a recent editorial in the British Medical Journal on protecting breast-feeding from breast milk substitutes, it was stated that the code mentioned is widely violated and needs monitoring and supporting ${ }^{1}$. In a comment, 'Breastmilk-substitute business booms in Italy', it was reemphasized that efforts to promote breast-feeding are minute compared with the marketing messages on baby milk substitutes in some European countries, and that in developing countries their marketing is much more aggressive $^{51}$. In Sri Lanka, while there is a national code regarding the marketing of formula milks, it is not properly enforced $^{52}$. In Bangkok, in a series of mothers questioned, $26 \%$ had received free samples of breast milk substitute, a feeding bottle or teat and infant formula ${ }^{53}$. As an illustration of consequences, in Africa, in a study made in Guinea-Bissau, it was reported that children at 12-35 months who were not breast-fed had a 3.5 times higher mortality than breast-fed children ${ }^{54}$. As mentioned earlier, a similar report was published in Chile?

The South African Code of Ethics for the Marketing of Breast Milk Substitutes was published in $1986^{55}$. Some major companies have become voluntary signatories. However, in Durban, a recent and widespread enquiry conducted on violations of the code, in 21 cluster areas, made on 800 pregnant women and mothers, revealed that $47.8 \%$ of health facilities had been visited by company personnel to provide product information to mothers, $2.3 \%$ had received free samples of a product, and $28 \%$ of mothers had received negative information on breastfeeding from a company ${ }^{6}$.

Since the problem at issue is not being satisfactorily coped with by western health authorities, with their advanced resources, the magnitude of the problem being faced in this respect in sub-Saharan Africa will be appreciated.

\section{Danger of breast-feeding beyond infancy}

It has been reported that breast-feeding when prolonged well beyond infancy in developing countries is often associated with relatively low nutritional status ${ }^{56}$. For example, in a review on 'Is prolonged breast-feeding associated with malnutrition?' it was stated that in a study made in Brazil on infants of $1-3$ years of age the prevalence of malnutrition was lowest in infants breast-fed for 3-6 months, but worse for those breast-fed for longer ${ }^{57}$. Hence, it has been considered that prolonged breastfeeding impairs growth. However, different conclusions have been reached in a number of studies. In a western setting, in the USA in Boston, the conclusion was reached that the inverse association between prolonged breastfeeding and growth in late infancy is not causal, but may be explained by poorer complementary feeding among breast-fed compared with weaned infants ${ }^{58}$. In Africa, in rural Senegal, it was found that length for age was associated with duration of breast-feeding. The median duration was 25.0 months for Z-scores of $<-2$, and 22.7 months for Z-scores of $>0{ }^{59}$. It was considered that women who prolong breast-feeding for undernourished infants, and who reduce the duration for well-nourished 
children, do so probably because they are aware of the increased mortality risk following weaning. In an investigation made in an urban area in Burkina Faso, no evidence was found to support the hypothesis that prolonged breast-feeding may be detrimental to children ${ }^{60}$. In a recent review, although it concerned the situation in rural China, it was concluded that for rural children in developing countries, mothers should be encouraged to breast-feed their children for the first 2 years of life, with the addition of good quality weaning foods from about $4-$ 6 months $^{61}$. In brief, in all situations, there must be variety in the weaning foods.

\section{HIV infection and breast-feeding}

What is the magnitude of this new problem? It has been reported that 20 million people are infected with HIV in sub-Saharan Africa ${ }^{62}$. In southern Africa, the proportions of antenatal mothers infected are believed to be the highest in the world. In series of antenatal mothers, the percentages who are HIV positive were given as $26 \%$ in South Africa ${ }^{63}$, and as high as $45 \%$ in Zimbabwe ${ }^{64}$. The risk of vertical transmission has been considered to be $20-$ $35 \%{ }^{65}$. In South Africa, in a follow-up of HIV-infected African women, the mean vertical transmission was found to be $34 \%{ }^{66}$.

The issue of crucial importance is: should infected mothers feed their babies, or not? $\mathrm{WHO}^{67}$ and UNICEF have recommended that in situations where infectious diseases are not the primary cause of infant deaths, HIVinfected women should be advised not to breast-feed but to use a safe feeding alternative. But in situations where the primary causes of deaths of infants are infections and malnutrition, breast-feeding should continue to be promoted and supported. In Africa, a crucial factor in the situation described is that most mothers who are infected with HIV are unaware of their condition; in a study made in Cape Town the proportion was $80 \%{ }^{68}$.

As to the effectiveness of current treatments, in Bangkok, Thailand, a short course of zidovudine was given orally twice daily to a series of infected mothers prior to delivery; in the absence of breast-feeding the drug lessened the risk of vertical transmission by half ${ }^{69}$. The drug was also given to series of infected mothers in Côte d'Ivoire and Burkina Faso during the postpartum period; after 6 months of breast-feeding the proportion of infants infected was $18.0 \%$ in the treated group, compared with $27.5 \%$ in the placebo group ${ }^{70}$.

There have been apprehensions over the cost-effectiveness of the antiviral treatment of mothers. In South Africa, it was considered that a budget which required the provision of a safe feeding alternative would be unaffordable $\mathrm{b}^{63,71}$. However, according to the World Development Report $^{72}$, antiviral interventions costing less than the equivalent of US\$100 per life saved are considered to be cost-effective for middle-income countries. Recently, the cost-effectiveness of options available in South Africa has been examined in detail ${ }^{73}$. The conclusion reached was that, on the one hand, in the more indigent countries where breast-feeding is associated with a strongly protective effect, or where the IMR exceeds 70-140 per 1000 live births, breast-feeding should be favoured. In contrast, it was considered that in South Africa, regarded as a middle-income country, formula feeding should be adopted. The reasons given were that the IMR in the latter country is generally below 50 per 1000 , there is a high level of spending on HIV-infected children, and the infrastructure is relatively sophisticated ${ }^{74}$. However, as has been emphasized ${ }^{6}$, application of this policy in a blanket manner does not take into account the considerable social, economic and other disparities which prevail within the country, so that policies regarding appropriate feeding practices under the conditions described should be determined at local level.

In a recent development, a prospective cohort study was made in Durban, South Africa, on the influence of infant feeding patterns on early mother-to-child transmission of HIV- $1^{75}$. It transpired that at 3 months there was a transmission of $24.1 \%$ in infants who received mixed feeding, $14.6 \%$ in those exclusively breast-fed and $18.8 \%$ in infants who were never breast-fed. In an editorial comment $^{76}$, and in correspondence ${ }^{77}$, it was emphasized that confirmation and further research is required. Enquiries must include investigating: (i) the acceptability of exclusive breast-feeding and early weaning; (ii) whether a regimen of exclusive breast-feeding for 3 months followed by early and complete weaning is practicable; and (iii) on whether this regimen will prejudice the highly important promotion of breast-feeding in the general population.

While current very intensive research continues, both in relation to the availability of a vaccine and the more effective treatment of the infection, the problem at issue is one of huge magnitude, which could worsen. In many countries in sub-Saharan Africa, especially those in southern Africa, the infection rate is increasing rapidly. In such countries, it has been estimated that a large decrease in years of life expectancy is inevitable in the very near future $^{78}$. In this connection, in a recent study made in Zimbabwe, the survival time by 2002 has been considered to be likely to decrease from 63 to 47 years ${ }^{79}$.

\section{Discussion}

As emphasized by WHO, a huge burden of mortality from the absence of or from inadequate breast-feeding is being borne by developing populations. In developed populations, 99\% of infants now survive their first birthday. Accordingly, in such contexts, whether breast-feeding is practised or not has little bearing on mortality in the first year of life. This mortality situation thus stands in gross 
contrast to that prevailing in indigent developing populations. In Africa, at the extreme, in Sierra Leone only $66 \%$ of infants reach their first birthday ${ }^{80}$. However, in Cape Town, under far better circumstances, $97.5 \%$ of African infants survive their first year ${ }^{81}$.

As will have been appreciated, the outlook for breastfeeding in African mothers in general is one of gloom. On the positive side, there is increasing health education, initiatives from 'baby friendly hospitals', some social support (maternity leave, availability of crèches at the workplace and elsewhere), and the code of marketing of breast milk substitutes ${ }^{82}$. Negative and discouraging influences include certain clinic and hospital practices, and the promotion of breast milk substitutes. The very serious problem linked with HIV infection will remain acute. Further, the pressure to use breast milk substitutes and weaning foods earlier than might be needful, especially in urban areas, will continue. The giving of greater encouragement to breast-feeding by health authorities could well induce more mothers to breast-feed and to lengthen the period of lactation. As an example, in Nigeria, in an endeavour to increase breast-feeding in a rural community, of women who were given counselling before and after delivery, 39.8\% were breast-feeding at 4 months compared with $13.9 \%$ in the control group ${ }^{83}$. But against this hope, and this applies to primary health care practices, generally, it must be faced that in the African context, a drawback of great moment is the fact that virtually all clinics and hospitals are habitually short staffed and are overloaded with patients. Hence, endeavours to devote more time to encourage breast-feeding is essentially limited. Also to be taken into account is the situation that in many African countries, medical help is almost unattainable when needed by the masses. In Nigeria, it has been stated that the vast majority of the population has virtually no access to hospitals, clinics or to health professionals ${ }^{84}$. Other adverse features in the present African scenario are: in Kenya, infant deaths are increasing; in Zambia fewer children are being immunized; in Tanzania, primary school enrolment has fallen; and in Zimbabwe the seeking of health care is decreasing ${ }^{85}$. At the other extreme, where there are better resources and facilities, as in South Africa, by no means all expectant mothers seek help at clinics ${ }^{86}$, although lately an increasing proportion do so since such services are now free ${ }^{87}$.

In all of the situations of despondency described, and accepted by most as near inevitable, there are examples, isolated admittedly, which demonstrate that with education, cooperation and determination, success can be achieved. Thus, in the Gambia, in a series of villages at three centres over a 10-year period, 1975-1984, local measures, without excessively high expenditure, had the effect of reducing IMR from 124 to 25 per 1000 - chiefly by making available 24-hour attention by a nurse or doctor at clinics and hospitals $^{88}$. Nowadays, however, in virtually all African countries, the services of nurses and doctors are limited.
Perhaps the most outstanding example of successful health policy is that demonstrated by Kerala, almost the poorest of states in India, yet with a very low IMR of 17 per 1000 live births ${ }^{89}$, which is the same as that of Africans in the USA ${ }^{90}$, the richest country in the world. The remarkable changes could not have been accomplished without there being a high level of successful breast-feeding. Far more should be known of these isolated but unquestionable examples of success which have been achieved in poor communities/countries. While such performances tend to mitigate the general gloom, the outlook can only be lightened by the concerted action of individuals, communities and health authorities.

It will be apparent that the outlook for breast feeding in the year 2000 and beyond - a practice so important for the health of infants in largely impoverished African populations - depends on many factors, perhaps the most important of which is the early control of HIV infection and its level of transmission.

\section{Acknowledgements}

Gratitude is expressed for financial assistance from the South African Institute for Medical Research Foundation, the Medical Research Council, the Cancer Association of South Africa and the South African Sugar Association. Thanks are due to Mrs BF Walker for library and other assistance, and to those who made helpful suggestions, including Professor JCA Davies, Dr J McKeown and Dr U MacIntyre.

\section{References}

1 Costello A, Sachdev HS. Protecting breast feeding from breast milk substitutes. BMJ 1998; 316: 1103-4.

2 World Health Organization. Infant and Young Child Nutrition. Geneva: WHO, 1993.

3 Golding J, Emmett P, Rogers IS. Breast feeding and infant mortality. Early Hum. Develop. 1997; 49 (Suppl.): S143-55.

4 Hendershot GE. Trends in breastfeeding. Pediatrics 1984; 74 (Suppl.): 591-602.

5 Faber M, Oelofse A, Kriek JA, Benadé AJS. Breastfeeding and complementary feeding practices in a low socioeconomic urban and low socioeconomic rural area. South Afr. J. Food Sci. Nutr. 1998; 9: 200-8.

6 Moodley J, Saitowitz R, Linley L. A review of the literature on breast-feeding - policy and research issues. S. Afr. Med.J. 1999; 89: 681-7.

7 Jelliffe DB, Jelliffe EFP. 'Breast is best': modern meanings. N. Engl. J. Med. 1977; 297: 912-5.

8 Cuthbertson WFJ. Evolution of infant nutrition. Br. J. Nutr. 1999; 81: 359-71.

9 Plank SJ, Milanesi ML. Infant feeding and infant mortality in rural Chile. Bull. World Health Organ. 1973; 48: 203-10.

10 Bwibo NO. Breastfeeding: past, present and future. East Afr. Med.J. 1995; 72: 145-6.

11 Jackson R. Doctors and Diseases in the Roman Empire London: British Museum Press, 1988; 86-111.

12 Department of Health and Social Security. Present-Day Practice in Infant Feeding. Department of Health and Social Security Report on Health and Social Subjects No. 9. London: Her Majesty's Stationery Office, 1974; 38. 
13 Fomon SJ. Reflections on infant feeding in the 1970s and 1980s. Am. J. Clin. Nutr. 1987; 46 (Suppl. 1): 171-82.

14 Richardson BD. Breast versus bottle feeding. S. Afr. Med.J. 1978; 53: 1010.

15 Leary PM. Infant feeding today. S. Afr. Med. J. 1976; 50: $1271-2$.

16 Ryan AS, Rush D, Krieger FW, Lewandowski GE. Recent declines in breast-feeding in the United States, 1984 through 1989. Pediatrics $1991 ; \mathbf{8 8}: 719-27$.

17 Vestermark V, Hogdall CK, Plenov G, Birch M, ToftagerLarsen K. The duration of breast-feeding. A longitudinal prospective study in Denmark. Scand.J. Soc. Med. 1991; 19: 105-9.

18 Cadwell K. Reaching the goals of 'Healthy People 2000' regarding breastfeeding. Clin. Perinatol. 1999; 26: 527-37.

19 Wylie J, Verber I. Why women fail to breast-feed: a prospective study from booking to 28 days post-partum. J. Hum. Nutr. Diet. 1994; 7: 115-20.

20 Gelfand M. Medicine in Tropical Africa. Edinburgh: E \& S Livingstone, 1961; 114-5.

21 Walker ARP. Infant feeding practices in South Africa. S. Afr. Med.J. 1978; 54: 820-2.

22 Watson AR. Breast versus bottle feeding. S. Afr. Med.J. 1978; 54: 118.

23 Population Reference Bureau. Breastfeeding Patterns in the Developing World. Washington, DC: United States Agency for International Development, 1999.

24 Perez-Escamilla R. Update on the breastfeeding situation in Africa. Nutr. Res. 1993; 13: 597-609.

25 Jooste PL, Langenhoven ML, Kriek JA, Kunneke E, Nyaphisi $\mathrm{M}$, Sharp B. Nutritional status of rural children in the Lesotho Highlands. East Afr. Med.J. 1997; 74: 680-9.

26 Steyn NP, Badenhorst CJ, Nel JH, Ladzani R. Breast-feeding and weaning practices of Pedi mothers and the dietary intakes of their preschool children. S. Afr. J. Food Sci. Nutr. 1993; 5(1): 10-3.

27 Roberts GJ, Cleaton-Jones PE, Richardson BD, Sinwell RE, Lucas VS. Breast and bottle feeding in rural and urban South African children. J. Hum. Nutr. Diet. 1995; 8: 25563.

28 Delport SD, Becker PJ, Bergh A. Growth feeding practices and infections in Black infants. S. Afr. Med.J. 1997; 87: 5761.

29 Bamisaiye A, Oyediran MA. Breast-feeding among female employees at a major health institute in Lagos, Nigeria. Soc. Sci. Med. 1983; 17: 1867-71.

30 Ighogboja IS, Odumodu CU, Olarewaju RS. Breastfeeding pattern in Jos, Nigeria, before baby friendly hospital initiative. J. Trop. Pediatr. 1996; 42: 178-9.

31 El Bushra HM, Salih MA, Satti SA, Ahmed M el F, Kamil IA. Infant-feeding practices in urban and rural communities of the Sudan. Trop. Geogr. Med. 1994; 46: 309-12.

32 Ibrahim MM, Persson LA, Omar MM, Wall S. Breast feeding and the dietary habits of children in rural Somalia. Acta Paediatr. 1992; 81: 480-3.

33 Franklin RR, Bertrand WE, Mock NB, Nkamany K, McCaw A. Feeding patterns of infants and young children in Kinshasa, Zaire. J. Trop. Pediatr. 1993; 29: 255-9.

34 Izatt SD. Breastfeeding counseling by health care providers. J. Hum. Lact. 1997; 13: 109-13.

35 Abels J. Breast-feeding. BMJ 1949; 1: 154.

36 Antonov AN. Children born during the siege of Leningrad in 1942. J. Pediatr. 1947; 30: 250-9.

37 Smith CA. Effects of maternal undernutrition upon the newborn infant in Holland (1944-1945). J. Pediatr. 1947; 30: 229-43.

38 Williams CD. Nutritional conditions among women and children in internment in the civilian camp at Singapore. Proc. Nutr. Soc. 1946; 5: 127-33.

39 WHO Expert Committee. Nutrition in Pregnancy and
Lactation. Technical Report Series No. 302. Geneva: World Health Organization, 1965.

40 Vogel AM, Mitchell EA. The establishment and duration of breastfeeding. Part 1: hospital influences. Breastfeed. Rev. 1998; 6: 5-9.

41 Pantazi M, Jaeger MC, Lawson M. Staff support for mothers to provide breast milk in pediatric hospitals and neonatal units. J. Hum. Lact. 1998; 14: 291-6.

42 Bella $\mathrm{H}$. Are health workers adequately trained to manage and promote breastfeeding? Saudi Med.J. 1998; 19: 441-5.

43 Trowell HC. Non-Infective Disease in Africa. London: Edward Arnold, 1960; 327-31.

44 Jelliffe DB, Jelliffe EFP. The uniqueness of human milk. An overview. Am. J. Clin. Nutr. 1971; 24: 1013-7.

45 Power DJ, Willoughby W, de Waal RH. Breastfeeding in Cape Town. S. Afr. Med.J. 1979; 56: 718-21.

46 Maasdorp J, Loenig W. Are breast-feeding problems iatrogenic? S. Afr. Med.J. 1989; 77: 397.

47 Health Systems Trust. South African Health Review. Durban, South Africa: Health Systems Trust, 1997; 209-10.

48 Annotation. War on baby foods. Lancet 1974; i: 719-20.

49 Leading article. The infant-food industry. Lancet 1976; ii: 503.

50 WHO/UNICEF. The WHO/UNICEF International Code of Marketing of Breastmilk Substitutes. Geneva: World Health Organization, 1981.

51 Simini B. Breast-milk-substitute business booms in Italy Lancet 1999; 353: 1077.

52 Perera T. National code of marketing of formula milks is not properly enforced in Sri Lanka. BMJ 1999; 318: 1140.

53 Taylor A. Violations of the international code of marketing of breast milk substitutes: prevalence in four countries. BMJ 1998; 316: 1117-22.

54 Molbak K, Gottschau A, Aabyy O, Hojlyng N, Ingholt L, da Silva AP. Prolonged breastfeeding, diarrhoeal disease, and survival of children in Guinea-Bissau. BMJ 1994; 308: 14036.

55 Department of National Health. South African Code of Ethics for the Marketing of Breast Milk Substitutes. Pretoria: DNHPD, 1986.

56 Waterlow JC, Thomson AM. Observations on the adequacy of breastfeeding. Lancet 1979; ii: 238-42.

57 Victora CG, Vaughan JP, Martines JC, Baecelos LB. Is prolonged breast-feeding associated with malnutrition? Am. J. Clin. Nutr. 1984; 39: 307-14.

58 Fawzi WW, Herrera MG, Nestel P, el Amin A, Mohamed KA A longitudinal study of prolonged breastfeeding in relation to child malnutrition. Int. J. Epidemiol. 1998; 27: 255-60.

59 Simondon KB, Simondon F. Mothers prolong breastfeeding of undernourished children in rural Senegal. Int.J. Epidemiol. 1998; 27: 490-4.

60 Cousens S, Nacro B, Curtis V, et al. Prolonged breastfeeding: no association with increased risk of clinical malnutrition in young children in Burkina Faso. Bull. World Health Organ. 1993; 71: 713-22.

61 Prentice A. Extended breast-feeding and growth in rural China. Nutr. Rev. 1994; 52: 144-6.

62 Nduati R. Breastfeeding: a complex intervention in the 21st century. East Afr. Med. J. 1998; 75: 441-2.

63 Wilkinson D, Floyd K, Gilks CF. Antiretroviral drugs as a public health intervention for pregnant HIV-infected women in rural South Africa: an issue of cost-effectiveness and capacity. AIDS 1998; 12: 1675-82.

64 Amanor Wilks D. Zimbabwe attempts to prevent health crisis. Lancet 1996; 347: 609.

65 Working Group on Mother-to-Child Transmission of HIV Rates of mother-to-child transmission of HIV-1 in Africa, America and Europe: results from 13 perinatal studies. J. Acquir. Immune Defic. Syndr. Hum. Retrovirol. 1995; 8: 506-10. 
66 Bobat R, Coovadia H, Moodley D, Coutsoudis A. Mortality in a cohort of children born to HIV-1 infected women from Durban, South Africa. S. Afr. Med.J. 1999; 89: 646-8.

67 World Health Organization. Consensus Statement from the WHO/UNICEF Consultation on HIV Transmission and Breastfeeding. Geneva: Global Programme on AIDS, 1992.

68 Kuhn L, Mathews C, Fransman D, Dikweni L, Hussey G. Child feeding practices of HIV-positive mothers in Cape Town, South Africa. AIDS 1999; 13: 144-6.

69 Shaffer N, Chuachoowong R, Mock PA, et al. Short-course zidovudine for perinatal HIV-1 transmission in Bangkok, Thailand: a randomised controlled trial. Lancet 1999; 353: 773-80.

70 Dabis F, Msellati P, Meda N, et al. Six-month efficacy, tolerance and acceptability of a short regimen of oral zidovudine to reduce vertical transmission of HIV in breastfed children in Côte d'Ivoire and Burkina Faso: a double-blind placebo-controlled multicentre trial. Lancet 1999; 353: 786-92.

71 Wilkinson D, Karim SSA, Coovadia HM. Short course antiretroviral regimens to reduce maternal transmission of HIV. BMJ 1999; 318: 479-80.

72 World Bank. World Development Report, 1993 - Investing in Health. New York: Oxford University Press, 1993.

73 Söderlund N, Zwi K, Kinghorn A, Gray G. Prevention of vertical transmission of HIV: analysis of cost effectiveness of options available in South Africa. BMJ 1999; 318: 1650-6.

74 Kinghorn AW. Projections of the Costs of Anti-Retroviral Infections to Reduce Mother-to-Child Transmission of HIV in the South African Public Sector. HIV Management Services Technical Report. Johannesburg: HIV Management Services, 1998.

75 Coutsoudis A, Pillay K, Spooner E, et al. Influence of infantfeeding patterns on early mother-to-child transmission of HIV-1 in Durban, South Africa: a prospective cohort study. Lancet 1999; 354: 471-6.
76 Newell M-L. Breastfeeding and HIV infection: a global perspective. Hosp. Med. 1999; 60: 778-9.

77 Newell M-L. Infant feeding and HIV-1 transmission. Lancet 1999; 354: 442-3.

78 Editorial. Half the story. HIV may have started there, but Africa shouldn't bear the burden. New Sci. 1999; 161: 3 .

79 Logie D. AIDS cuts life expectancy in sub-Saharan Africa by a quarter. BMJ 1999; 319: 806.

80 Logie D. Unexpected always happens. Lancet 1996; 347 : 1819-20.

81 Medical Officer of Health. Annual Report, Vol. 2. Cape Town: 1996/97; 2.

82 Malik ANJ, Cutting WAM. Breast feeding: the baby friendly initiative. BMJ 1998; 316: 1548-9.

83 Davies-Adetugbo AA. Promotion of breast feeding in the community: impact of health educational programme in rural communities in Nigeria. J. Diarrhoeal Dis. Res. 1996; 14: $5-11$.

84 Kaufman JS, Asuzu MC, Rotimi CN, Johnson OO, Owoaje EE, Cooper RE. The absence of adult mortality data for subSaharan Africa: a practical solution. Bull. World Health Organ. 1997; 75: 389-95.

85 News. African research - a key role. Afr. Health 1999; 21: 40.

86 Haffejee IE. Breast-feeding - advantages and methods of promotion. Contin. Med. Edu. 1990; 8: 1072-7.

87 Wagstaff LA, Chimere-Dan OD, Ramontja RM. A survey of health issues in a South African urban community comparing findings from formal and informal dwellers. South Afr. J. Epidemiol. Infect. 1997; 12: 55-60.

88 Lamb WH, Foord FA, Lamb CMB, Whitehead RG. Changes in maternal and child mortality rate in three isolated Gambian villages over 10 years. Lancet 1984; ii: 1819-20.

89 Abbasi K. The World Bank and world health focus on South Asia - II. India and Pakistan. BMI 1999; 318: 1132-5.

90 Anonymous. Infant mortality - United States, 1992. Morbid. Mortal. Weekly Rep. 1994; 43: 905-9. 